\title{
Sparse and Selective Odor Coding by Mitral/Tufted Neurons in the Main Olfactory Bulb
}

\author{
Ian G. Davison and Lawrence C. Katz ${ }^{\dagger}$ \\ Howard Hughes Medical Institute and Department of Neurobiology, Duke University Medical Center, Durham, North Carolina 27710
}

The mammalian olfactory system recognizes an enormous variety of odorants carrying a wide range of important behavioral cues. In the main olfactory bulb (MOB), odorants are ultimately represented through the action potential activity of mitral/tufted cells (M/Ts), whose selectivity and tuning to odorant molecules are therefore fundamental determinants of MOB sensory coding. However, the sheer number and diversity of discrete olfactory stimuli has been a major barrier to comprehensively evaluating M/T selectivity. To address this issue, we assessed M/T odorant responses in anesthetized mice to a 348-odorant panel widely and systematically distributed throughout chemical space, presented both individually and in mixtures at behaviorally relevant concentrations. We found that $\mathrm{M} / \mathrm{T}$ activation by odorants was markedly selective, with neurons responding robustly, sensitively, and reliably to only a highly restricted subset of stimuli. Multiple odorants activating a single neuron commonly shared clear structural similarity, but M/T tuning also frequently extended beyond obviously defined chemical categories. Cells typically responded to effective compounds presented both individually and in mixtures, although firing rates evoked by mixtures typically showed partial suppression. Response selectivity was further confirmed in awake animals by chronic recordings of $\mathrm{M} / \mathrm{Ts}$. These data indicate that individual M/Ts encode specific odorant attributes shared by only a small fraction of compounds and imply that the MOB relays the collective molecular features of an odorant stimulus through a restricted set of M/Ts, each narrowly tuned to a particular stimulus characteristic.

Key words: sensory coding; olfactory bulb; in vivo; mitral cell; receptive field; odor; mixture

\section{Introduction}

Smell carries critical cues about food, predators, and social information through a vast, highly diverse set of volatile odorants, which the olfactory system must accurately identify. Odor information is ultimately encoded in the mammalian main olfactory bulb (MOB) by action potentials of mitral/tufted cells $(\mathrm{M} / \mathrm{Ts})$, which form its sole output to cortex. The form of MOB sensory representations will therefore be manifested in $\mathrm{M} / \mathrm{T}$ response properties across a range of odorants. Odorants may be encoded by activity patterns broadly distributed across a large population of nonselective M/Ts, each carrying little precise stimulus information (Lehmkuhle et al., 2003, 2006; Mazor and Laurent, 2005), or may alternatively be represented by selective activation of distinct sets of neurons, each recognizing specific molecular attributes of a volatile compound (Ressler et al., 1994; Mori et al., 1999). Although molecular and functional mapping of sensory input layers has revealed key features of MOB processing (Buck and Axel, 1991; Rubin et al., 1999; Wachowiak and Cohen, 2001), these signals primarily reflect organization of presynaptic sensory

\footnotetext{
Received Aug. 30, 2006; revised Jan. 19, 2007; accepted Jan. 21, 2007.

This work was supported by the Howard Hughes Medical Institute and National Institutes of Health Grant R01 DC005671. We thank Drs. R. Mooney, M. Ehlers, D. Fitzpatrick, S. Shea, Y. Ben-Shaul, and B. Arenkiel for thoughtfu discussion and reading of this manuscript and M. Ehlers, R. Mooney, and D. Fitzpatrick for generous continued support and scientific advice. This manuscript is dedicated to the memory of Larry Katz.

${ }^{\dagger}$ Deceased Nov. 26, 2005

Correspondence should be addressed to lan G. Davison, Howard Hughes Medical Institute and Department of Neurobiology, Duke University Medical Center, Box 3209, Durham, NC 27710. E-mail: davison@neuro.duke.edu. D0I:10.1523/JNEUROSCI.3779-06.2007

Copyright $\odot 2007$ Society for Neuroscience $\quad$ 0270-6474/07/272091-11\$15.00/0
}

neuron inputs (Gurden et al., 2006), and the characteristics of $\mathrm{M} / \mathrm{T}$ tuning and selectivity underlying $\mathrm{MOB}$ odor coding remain in debate.

A major difficulty in establishing $\mathrm{M} / \mathrm{T}$ tuning is effectively sampling olfactory space, composed of thousands of discrete compounds varying along multiple dimensions. Constrained stimulus sets may incompletely sample relevant compounds, giving a misleading estimate of receptive range and selectivity. Effective assessment of tuning thus requires extensive and systematic testing with large odorant panels (Hallem and Carlson, 2006). Perhaps partly because of this issue, previous measurements of $\mathrm{M} / \mathrm{T}$ tuning have yielded conflicting results. At one extreme, $\mathrm{M} / \mathrm{Ts}$ were activated by a single chemical component of $>100$ volatiles in urine (Lin et al., 2005), although this could reflect specialized processing of important social stimuli. In other studies, $\mathrm{M} / \mathrm{Ts}$ responded to subsets of related compounds within a defined structural class, although selectivity across broader chemical categories was not addressed (Imamura et al., 1992; Mori et al., 1992; Katoh et al., 1993). Still other studies found relatively indiscriminate activation by various stimuli within small odorant panels (Motokizawa, 1996; Lehmkuhle et al., 2003, 2006). Analogous neurons in the insect antennal lobe appear broadly tuned (Perez-Orive et al., 2002; Mazor and Laurent, 2005), although other insect findings support selectivity (Wang et al., 2003). Thus, the sensory encoding scheme of the MOB remains unclear because of sampling difficulties and inconsistent experimental findings across various stimulus sets and paradigms. 
To directly assess MOB outputs, we screened M/Ts in anesthetized mice with a panel of $\sim 350$ compounds broadly and systematically dispersed across odorant space. M/T odorant responses were markedly selective, evoked sensitively and reliably by only a small subset of compounds, whether presented alone or in mixtures. Coactive stimuli often shared overt structural similarity but were not necessarily limited to clear chemical categories. Chronic recordings in alert mice showed that selectivity also contributes to processing in awake animals. These data suggest that odor information is encoded in the MOB by selectively tuned $\mathrm{M} / \mathrm{Ts}$ that represent specific characteristics of odorant molecules.

\section{Materials and Methods}

Anesthetized single-unit recording. In vivo extracellular recordings were made from olfactory bulbs of 53 C57BL/ 6 mice of both sexes between 10 and 24 weeks of age. Mice were maintained on a $12 \mathrm{~h}$ light/dark cycle and received food and water ad libitum. Surgical anesthesia was induced by a ketamine/xylazine mixture $(200 / 50 \mathrm{mg} / \mathrm{kg})$ supplemented by atropine $(0.2 \mathrm{mg} / \mathrm{kg}$; Sigma, St. Louis, MO). Animals were placed in a custom stereotax, and the dorsal olfactory bulb was exposed through a small craniotomy and stabilized with agarose $(2-3 \% \mathrm{w} / \mathrm{v})$. After surgery, anesthesia was switched to sevoflurane $(2-3 \%, 1.8 \mathrm{~L} / \mathrm{min}$ in charcoal-filtered and moisturized $\mathrm{O}_{2}$ ). Body temperature was maintained at $36-37^{\circ} \mathrm{C}$, animals were freely breathing, and depth of anesthesia was monitored throughout by heart and respiration rates along with lack of response to toe or tail pinch. Single units were isolated and amplified using a commercially available amplifier (MiniMatrix; Thomas Recording, Giessen, Germany) and 1.5-4 M $\Omega$ quartz-coated tungsten electrodes. Units were identified as $\mathrm{M} / \mathrm{T}$ cells based on recording depth, clear changes in background neuronal activity across layers, electrophysiological criteria, and, in some cases, electrolytic lesioning of the recording site (supplemental Fig. 1, available at www.jneurosci.org as supplemental material). All animal experiments were performed in strict accordance with the guidelines of the National Institutes of Health and the Duke University Institutional Animal Care and Use Committee.

Odor presentation. We used an olfactometer based on a liquiddispensing robot (model 7200; I \& J Fisnar, Fair Lawn, NJ), which held interchangeable racks each containing 64 sampler vials ( 62 odorants, one blank stimulus of mineral oil, and one connected to vacuum for removing residual odorants between presentations). Custom Matlab software (MathWorks, Natick, MA) controlled robot movement and valve opening for sampling at each vial position, switching between clean air and odorized flow (each $0.2 \mathrm{~L} / \mathrm{min}$ ), supplementing the $1.8 \mathrm{~L} / \mathrm{min}$ main flow. Odorants were diluted in mineral oil according to their individual vapor pressures to give a nominal headspace concentration of $100 \mathrm{ppm}$ (compensating for widely varying volatility across odorants at $20^{\circ} \mathrm{C}$ and approximately normalizing stimulus strength) and further flow diluted to a nominal final vapor phase concentration of $10 \mathrm{ppm}$. We note that 10 ppm refers to final vapor phase concentration rather than a $10^{-5}$ dilution of the compound; the fluid-phase dilution for most odorants was $<1$ : 1000 , a range consistent with a large body of previous imaging and physiology studies (supplemental Fig. 2, available at www.jneurosci.org as supplemental material). For mixture stimuli, structural similarity of individual compounds within each mixture was minimized to reduce the potential for receptor cross-activation by multiple odorants. Odors were presented for $3 \mathrm{~s}$ in randomized order and repeated over three trials for each compound. Odorants used in various experiments are listed in supplementary Table 1 (available at www.jneurosci.org as supplemental material) and were obtained from either Sigma or International Flavors and Fragrances (New York, NY).

Awake recordings. Miniature motorized microdrives (Fee and Leonardo, 2001) containing three independently movable microelectrodes were chronically implanted on 12 - to 24 -week-old female C57BL/6 mice as described previously (Luo et al., 2003). Animals were anesthetized as described above, electrodes were inserted into the brain through a small craniotomy immediately posterior to the olfactory bulb, and the drive was cemented to the skull with dental acrylic. Electrodes (2-5 M $\Omega$; MicroProbe, Gaithersburg, MD) passed through the olfactory bulb at an angle of $\sim 45^{\circ}$ to the dorsal surface, allowing recording of $\mathrm{M} / \mathrm{T}$ neurons in the ventral and sometimes also the dorsal mitral cell layers, identified as under anesthesia. Animals were left to recover for $\geq 48 \mathrm{~h}$ after surgery and were clearly healthy, alert, and active at the time of recording. For passive odorant testing, animals were placed in a small, clean $500 \mathrm{ml}$ chamber, and filtered, moisturized air flowed through the chamber at 10 $\mathrm{L} / \mathrm{min}$ so that the volume of the chamber is exchanged in $\sim 2-3 \mathrm{~s}$. Odorants were presented with a system similar to that used in anesthetized experiments, but with $250 \mathrm{ml}$ sampler jars, 9 and $1 \mathrm{~L} / \mathrm{min}$ flow rates for main and odor delivery lines, respectively, and manual stimulus selection. The primary screen of $\mathrm{M} / \mathrm{Ts}$ in awake animals used 25 mixtures of four odorants each (supplemental Table 1, available at www.jneurosci. org as supplemental material).

Data analysis. For each trial, we collected data for either $12 \mathrm{~s}$ ( $6 \mathrm{~s}$ each of prestimulus and poststimulus periods, anesthetized animals) or $20 \mathrm{~s}$ (10 s each prestimulus and poststimulus, awake animals). Responses were quantified for each individual trial as a peristimulus time histogram (PSTH) (500 ms bins) of change in firing relative to baseline activity, which was calculated as the mean firing rate during prestimulus time intervals. Three trials were averaged for each odorant. A significant number of cells were virtually silent at rest, complicating statistical comparison of prestimulus and poststimulus activity, so a threshold of $5 \mathrm{~Hz}$ change in firing rate in any $500 \mathrm{~ms}$ histogram bin $(\sim 2.5$ spikes per respiration cycle) was used to classify cells as responsive or unresponsive to an odorant. This has the advantage of being a sensitive detection level (supplemental Fig. $2 B, C$, available at www.jneurosci.org as supplemental material) but frequently resulted in false positives $(\sim 7 \%$, evaluated during the prestimulus period) and thus overestimates the number of odorants eliciting a response. We therefore also report results using more conservative thresholds. If resting activity was high enough to permit statistical comparison of prestimulus and poststimulus rates, we also classified cells as responsive if firing rates in any bin exceeded 3 SDs of baseline. In some plots (see Figs. $2 B, 6$ ), responses are also shown as the average change in firing over the $3 \mathrm{~s}$ stimulus period. Because of the high variability in $\mathrm{M} / \mathrm{T}$ firing rates in awake animals, we classified neurons as responsive if they demonstrated a mean increase in firing of $5 \mathrm{~Hz}$. To eliminate ambiguity inherent in threshold-based binary classification of trials as responsive or nonresponsive, we also used a second selectivity statistic, lifetime response sparseness $\left(\mathrm{S}_{\mathrm{L}}\right)$, which is independent of detection threshold. $\mathrm{S}_{\mathrm{L}}$ was calculated as $\left(1-\left\{\left[\sum_{j=1}^{N} r_{j} / N\right]^{2} / \Sigma_{j=1}^{N}\left[r_{j}{ }^{2} /\right.\right.\right.$ $N]\}) /(1-1 / N)$, where $r_{j}$ is the response of the neuron to odorant $j$ (mean firing rate during $3 \mathrm{~s}$ odorant presentation, set to 0 if negative), and $N$ is the total number of odorants. This provides a measure of how much the response of a neuron is attributable entirely to one odorant (highly sparse, $\mathrm{S}_{\mathrm{L}}=1$ ) versus equally distributed across all odorants $\left(S_{L}=0\right)$ (Willmore and Tolhurst, 2001; Perez-Orive et al., 2002). Doseresponse functions were fit with a Hill equation of the form $y=\min +$ $(\max -\min ) /\left[1+\left(x_{1 / 2} / x\right)^{\text {rate }}\right]$ using Igor Pro (WaveMetrics, Eugene, OR). Structural similarity of odorant compounds was quantified using commercially available software (ChemTK; Sage Informatics, Santa Fe, $\mathrm{NM}$ ) to generate a 150-dimensional vector for each odorant, in which each dimension indicates the presence or absence of one of a predetermined list of structural descriptors. Odorant pairs were compared by calculating the number of descriptors shared by both compounds and normalizing this to the total number of descriptors present in the compound evoking a greater change in firing, to yield a fractional similarity index between 0 (no shared descriptors) and 1 (all descriptors shared).

\section{Results}

To assess the odorant tuning properties of MOB output neurons in vivo, we recorded extracellularly from single $\mathrm{M} / \mathrm{T}$ units in anesthetized mice while presenting a wide range of odorant stimuli. Recording locations were widely distributed across the dorsal, ventral, medial, and lateral MOB to minimize bias from sampling a restricted population (Fig. $1 A$, left). Units were classified as $\mathrm{M} / \mathrm{Ts}$ based on recording depth, clear changes in background activity across $\mathrm{MOB}$ layers, spike amplitude, firing pattern, and histological reconstruction of lesioned recording sites (supple- 
A

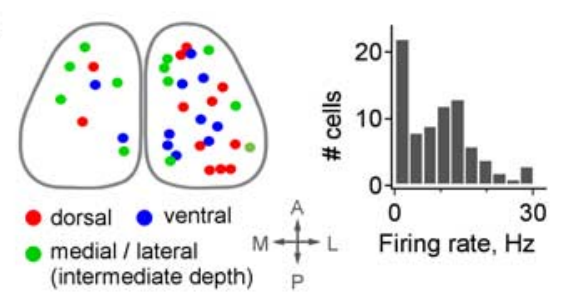

B

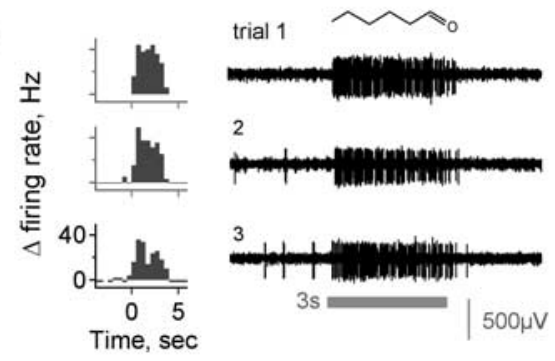

C

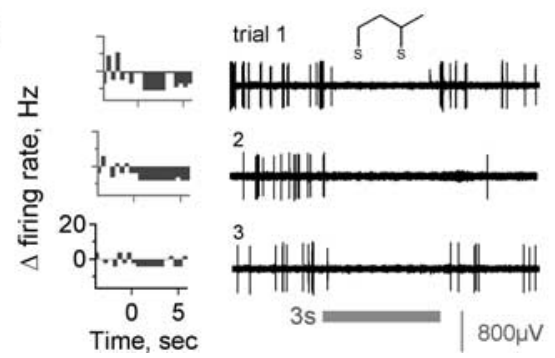

D
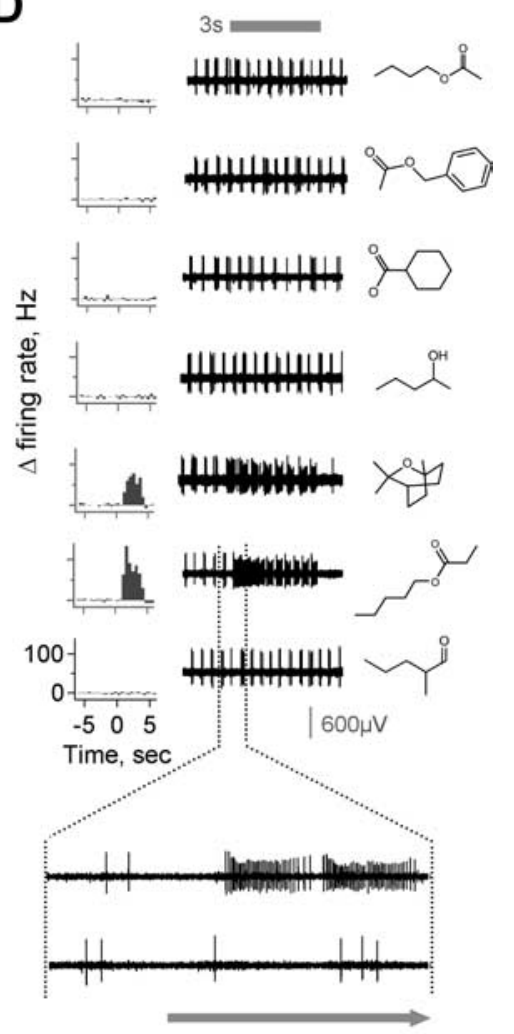

Figure 1. Robust $M / T$ activation by specific odorants. $A$, Composite map showing a dorsal view of recording sites, which were widely distributed on the dorsal, ventral, and medial/lateral MOB surfaces to avoid sampling bias. M/Ts have a broad range of spontaneous firing rates, from $\sim 0$ to nearly $30 \mathrm{~Hz}$; histogram shows population distribution. $\boldsymbol{B}, \boldsymbol{C}$, Both excitatory $(\boldsymbol{B})$ and inhibitory $(C) M / T$ responses are sustained during odorant presentation and consistent over multiple trials separated by extended time periods ( $\boldsymbol{B}$, C show separate cells). PSTHs (left) show firing rates calculated in $500 \mathrm{~ms}$ bins. $\boldsymbol{D}$, Raw data for five representative ineffective odorants (methyl butyrate, cyclohexanecarboxylic acid, benzyl acetate, 2-pentanol, and 2-methylvaleraldehyde) and two odorants evoking strong responses (eucalyptol and pentyl propionate). Bottom trace shows firing on expanded timescale. Firing rates exceed $150 \mathrm{~Hz}$ for some stimuli, illustrating the range of sensitivity of $\mathrm{M} / \mathrm{Ts}$ to different odorants. Gray bar indicates odor; all stimuli presented at $10 \mathrm{ppm}$ (see Materials and Methods). A, Anterior; D, dorsal; L, lateral; P, posterior.

mental Fig. $1 A$, available at www.jneurosci.org as supplemental material). M/Ts showed a wide range of spontaneous activity, with mean resting firing rates ranging from $\sim 0$ to $>20 \mathrm{~Hz}$ (Fig. $1 A$, right). Firing at rest was often coupled to respiration, as described previously (Buonviso et al., 2006), although the degree of coupling varied across cells (Wellis et al., 1989; Cang et al., 2003) (supplemental Fig. 1C, available at www.jneurosci.org as supplemental material).

\section{Mitral/tufted activation is robust, reliable, and stimulus specific}

Odorant stimulation could produce either excitation or suppression of $\mathrm{M} / \mathrm{T}$ firing, consistent with previous reports (Meredith, 1986; Wellis et al., 1989). Odor-evoked responses were reliable across multiple trials even when separated by extended time intervals and intervening presentation of many different stimuli (Fig. 1B,C). Responses typically began at first inhalation after odor presentation and almost invariably consisted of increases or decreases in firing sustained over the stimulus period rather than multiphasic responses with epochs of both (Meredith, 1986; Motokizawa, 1996). The most striking feature of $\mathrm{M} / \mathrm{T}$ responses, however, was their range of sensitivity to different odorants, even among compounds with similar chemical structures. Cells were unaffected by the majority of stimuli yet often showed strong increases in firing ( $\gg 40 \mathrm{~Hz}$ above baseline) to a small number of other odorants (Fig. 1D). Thus, when presented with an appropriate stimulus, $\mathrm{M} / \mathrm{T}$ s responded with robust changes in firing rate that were reliable and odorant-specific, clearly discriminating particular compounds in a single trial.

\section{$\mathrm{M} / \mathrm{T}$ odorant responses are highly selective}

As an initial evaluation of M/T odorant tuning, we screened cells with a panel of 25 monomolecular odorants with diverse chemical structures (supplemental Table 1, available at www.jneurosci.org as supplemental material), presenting three trials of each compound at a nominal vapor phase concentration of 10 ppm for $3 \mathrm{~s}$ (see Materials and Methods). Because odor-evoked changes in firing rate were robust and stimulus specific, we quantified responses using this measure [additional information may be further encoded by higher-order response characteristics such as synchrony (Kashiwadani et al., 1999)]. For a preliminary description of selectivity, we considered a neuron to be responsive to an odorant if its firing rate changed from baseline by $\geq 5$ $\mathrm{Hz}$ during any $500 \mathrm{~ms}$ time bin during odor presentation. This is a simple and intuitive measure that was close to the level of fluctuations in M/T firing at rest, was a small fraction of the size of evoked responses in many neurons, and could be applied to all recorded cells regardless of baseline activity (supplemental Fig. 2, Methods, available at www.jneurosci.org as supplemental material).

Responses of individual M/Ts to this odorant panel were markedly odorant specific. Vigorous firing was typically evoked by a small number of stimuli (Fig. $2 \mathrm{~A}$ ). In the vast majority of neurons, only a restricted set of odorants produced a significant change in firing rate (20 of 21 and 19 of 21 cells were activated or suppressed by $\leq 5$ odorants, respectively). Among these, responses often were clearly highest for one or two stimuli. Excitatory responses were typically the most pronounced, reaching sustained firing rates of $\sim 40-80 \mathrm{~Hz}$ in several cases, although cells also showed suppression of firing that was frequently stimulus specific (Fig. 2B). Whereas selectivity was clearest for strongly activated $\mathrm{M} / \mathrm{Ts}$, neurons with smaller changes in firing rate also demonstrated high stimulus specificity (Fig. $2 C$ ). Overall, M/Ts were activated by only a small fraction of the 25 odorants with an increase in firing rate: on average, $14.1 \%$ of stimuli elicited changes in firing of $\geq 5 \mathrm{~Hz}$ at any point during the stimulus (Fig. $2 C)(n=21$ cells in 10 mice). Thus, even using a sensitive criterion for detecting responses, $>80 \%$ of applied odorants were ineffective at either activating or inhibiting these neurons in our initial screen. Additionally, some cells showed minimal responses to all odorants, suggesting that they were tuned to stimuli not included in this panel. Selective tuning of M/Ts therefore provides a clear basis for identification of specific odorant compounds by single neurons. 
$\mathrm{M} / \mathrm{Ts}$ respond sensitively to odorants Behavioral detection of odorants by rodents is commonly highly sensitive (Passe and Walker 1985; Kelliher et al., 2003; Laska et al., 2006), raising the question of how sensitively single $\mathrm{M} / \mathrm{Ts}$ respond to odorants. We therefore assessed a concentration-response function for the most highly active odorant in six cells that responded robustly to one of the test compounds. M/T responses were monotonically graded with concentration and increased from threshold to saturation over approximately two to three orders of magnitude, approximately matching the dynamic range of glomeruli measured in functional imaging studies (Rubin and Katz, 1999; Wachowiak and Cohen, 2001) (Fig. 3A). Activation was uniformly excitatory at all concentrations in all cells tested, suggesting that these responses were determined primarily by excitatory sensory neuron input, although their activity may also be modulated by local inhibitory circuits. $\mathrm{M} / \mathrm{T}$ responses were highly sensitive and were activated by stimuli at concentrations well below our test range: all cells ( six of six) had response thresholds of $\leq 1 \mathrm{ppm}$ ( 10 times below test concentration), and four of six responded at $\leq 10$ parts per billion ( 1000 times below test concentration; $\mathrm{EC}_{50}$ of $0.57 \pm 0.87$ ppm, mean $\pm \mathrm{SD} ; n=6$ cells in 5 animals) (Fig. $3 B$ ). Responses of these cells were maximal at our test concentration of 10 ppm, regardless of a wide range of test odorant characteristics such as vapor pressure and molecular weight, again consistent with the fact that our test concentration was well above established rodent detection thresholds.

Besides determining the sensitivity of odorant responses, we also wanted to confirm that M/T selectivity was not an artifact of stimulus intensity. A selective neuron will have a receptive range that is narrow over a wide range of concentrations, whereas a broadly tuned neuron might appear selective because of marginal activation with odorant concentrations only slightly above its detection threshold. First, we note that behavioral thresholds are several orders of magnitude below our $10 \mathrm{ppm}$ test concentration in which behavioral data are available (Passe and Walker 1985; Kelliher et al., 2003; Laska et al., 2006). Also, although responses were sparse across the test panel, firing rates of many neurons increased by $\geq 40 \mathrm{~Hz}$, inconsistent with minimally suprathreshold responses. In addition, our odorants were delivered at concentrations comparable with or higher than those used in previous studies (supplemental Fig. 2, available at www.jneurosci.org as supplemental material), and many units in the granule cell layer consistently responded to a large fraction of test stimuli (data not shown), showing that our panel was effective at activating the MOB. Although it was not feasible to test the entire panel across a concentration series, $\mathrm{M} / \mathrm{Ts}$ responded to the most strongly preferred odorant over a drop in concentration of several orders of magnitude (Fig. $3 B$ ), demonstrating that their detection thresholds extend to intensities much lower than our test concentration. Although increasing odorant concentration recruits additional olfactory receptors (ORs) and M/Ts (Harrison and Scott, 1986; Wellis et al., 1989; Motokizawa, 1996; Hallem and Carlson, 2006), we found narrow $\mathrm{M} / \mathrm{T}$ receptive ranges even at concentrations far exceeding detection threshold, further consistent with a high degree of selectivity. Overall, these results demonstrate that $\mathrm{M} / \mathrm{T}$ responses are highly sensitive to compounds falling within their receptive range and that their selectivity at behaviorally relevant concentrations reflects their individual tuning properties rather than an artifact of testing near stimulus threshold. We thus conclude that the sparse activity we observe here provides sufficient information for odor identification at concentrations that clearly exceed rodent thresholds for behavioral detection and discrimination of odorants.

\section{Mixture responses reflect single-compound responses}

The marked selectivity of M/Ts tested with 25 odorants, particularly the fact that some neurons were unresponsive or minimally responsive to all compounds, indicated that an extensive stimulus set more representative of odorant space was needed to effectively measure $\mathrm{M} / \mathrm{T}$ tuning. To achieve this within recording time constraints, we evaluated responses to mixtures containing six individual odorants (Bozza et al., 2002), allowing testing of single neurons with a panel of over 300 odorants containing wide and systematic variation in chemical structure. Mixtures were used for the initial phase of testing for each cell, with each mixture composed of components with minimal overlap in chemical 
A

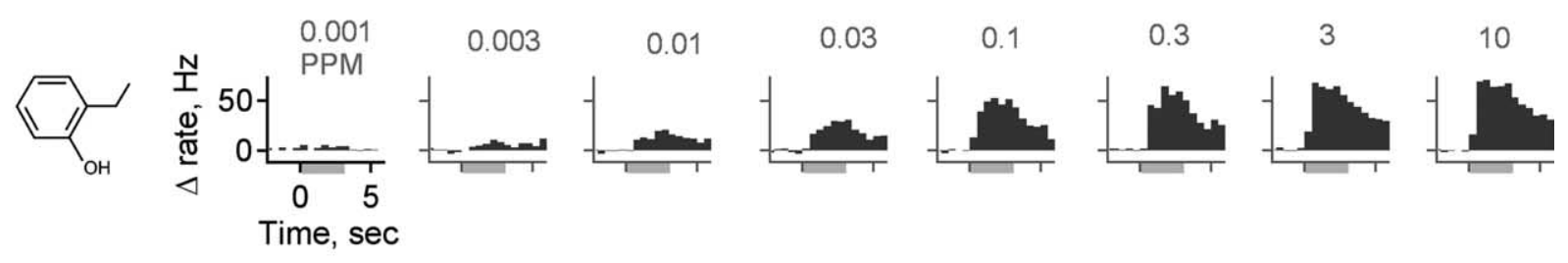

B

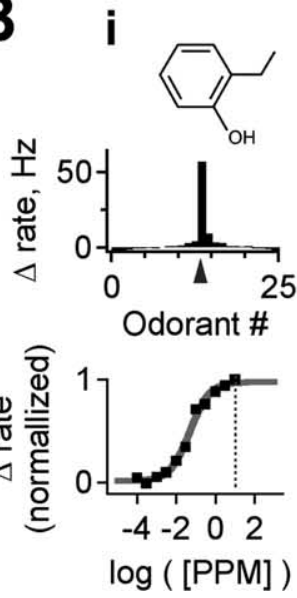

ii<smiles>CCCCC=O</smiles>
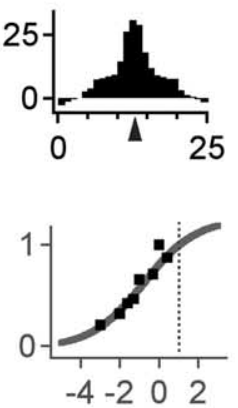

iii<smiles>CCCCCC(=O)CC</smiles>
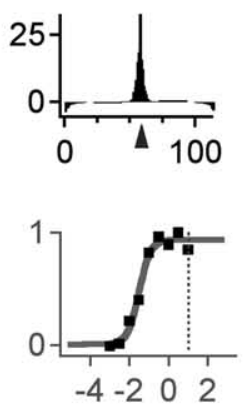

iv
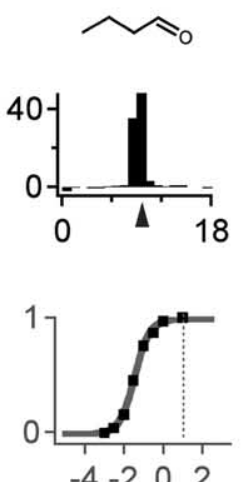

V
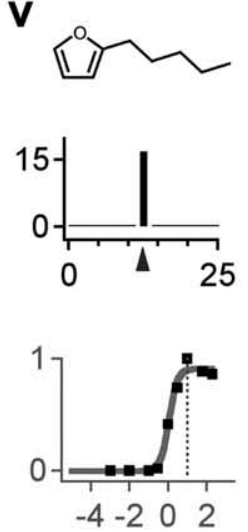

vi
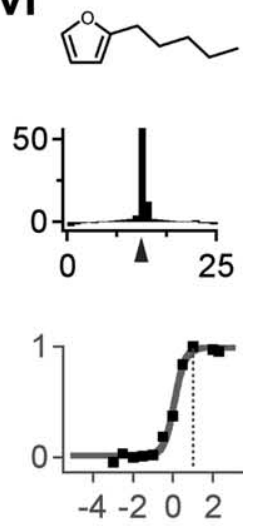

Figure 3. $M / T s$ are highly sensitive to odorants, with dynamic ranges well below the test concentration of our screen. $A, M / T$ activation, in this case to 2 -ethyl phenol, is graded smoothly and monotonically with stimulus intensity. The response of the cell is uniformly excitatory and sustained at all odorant concentrations, with a threshold $\leq 0.003 \mathrm{ppm}$. Bi-Bvi, Dose-response curves for six separate M/Ts strongly activated by different odorants. Top panels show the distribution of response strengths across odorants at $10 \mathrm{ppm}$ for each neuron, as well as the structure of the most highly active compound (indicated on histogram by arrowhead). Bottom, Dose-response function for the indicated compound, showing sensitive M/T odorant detection regardless of a range of vapor pressures or molecular weights at concentrations one to three orders of magnitude below the test panel concentration (indicated by dotted line) and indicating that narrow tuning is not a result of stimuli that weakly activate $M O B$ neurons.

A
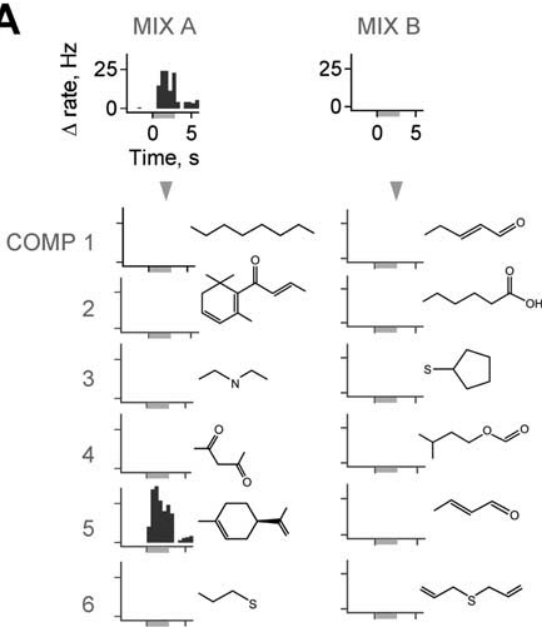

B
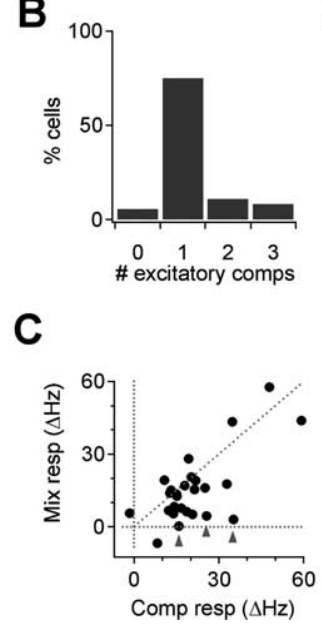

Figure 4. $M / T$ mixture responses correspond to individual compound responses. $\boldsymbol{A}$, Left, Cells responding to mixtures (Mix) typically respond to a single component (Comp). Right, The absence of a mixture response predicts the absence of responses to individual component compounds. PSTHs show changes in firing rate for a mixture (top) and its components (bottom); left and right panels are from the same neuron. $\boldsymbol{B}$, Histogram showing distribution of number of active components for all mixturecomponent data. A total of $75 \%$ of cells activated by a mixture respond to a single component compound. C, M/T firing rates are typically similar when active compounds are presented singly or in mixtures (diagonal line represents equal component and mixture responses), but, in the majority of cases, activation is slightly lower for mixtures (below the diagonal). A small number of responses were strongly suppressed when odorants were presented in mixtures compared with individually (arrowheads). $\boldsymbol{D}$, Pairwise comparison of firing rates evoked by components and mixtures. $E$, Average strength of mixture responses is lower than that for single compounds (52.4 $\pm 19.3 \%$, mean \pm SEM; $p<0.02, t$ test; $n=26)$.

structure. Once responses to mixtures were found, their components were individually tested for comparison as permitted by recording stability, along with the components of as many inactive mixtures as possible. Besides increasing the extent of screen-
D

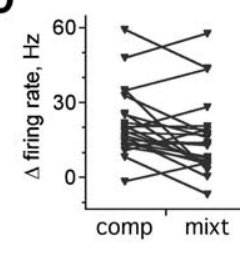

E

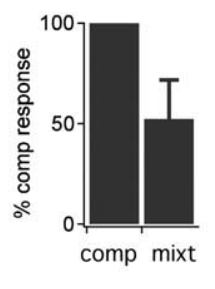

ing, this approach also allowed comparison of $\mathrm{M} / \mathrm{T}$ responses as they participate in MOB ensembles coding for monomolecular odorants versus mixtures, which constitute the vast majority of naturally occurring olfactory stimuli.

$\mathrm{M} / \mathrm{T}$ responses to mixtures consistently reflected their responses to individual constituent compounds. The presence of an excitatory mixture response accurately predicted a response to one or more components: overall, $94.4 \%$ of cells with a mixture response also showed a component response (Fig. 4A, left) (9330 cellodor pairs tested in mixtures, 1172 tested individually, 30 cells in 24 mice, response threshold of $5 \mathrm{~Hz}$ increase in firing per any $500 \mathrm{~ms}$ bin). Conversely, $82.6 \%$ of mixture presentations with no excitatory response also showed no component response (Fig. 4A, right). Although this mixture-component correlation was strong, it was diminished by substantial false positives generated by a sensitive but noisy response detection threshold $(\sim 7 \%$, evaluated during the prestimulus period). Using a more stringent threshold $(5 \mathrm{~Hz}$ mean change in firing rate during the $3 \mathrm{~s}$ odor presentation), the correspondence between mixtures and components increased to 95.8 and $98.7 \%$ for cells with and without responses, respectively. Most cells responded only to a single component of any of the mixtures, con- 
sistent with their structurally diverse composition (Fig. $4 A, B)(75 \%$ activated by a single component with a threshold of $\geq 5$ $\mathrm{Hz}$ /any time bin, $91.7 \%$ with threshold $\geq 10 \mathrm{~Hz}$ /any time bin). Relative response magnitudes were also preserved between mixtures and components in most cases, with odorants evoking the strongest mixture responses also producing the strongest component responses (data not shown). Thus, M/Ts typically responded to specific odorants regardless of whether they were presented singly or in mixtures, consistent with a role in the encoding of particular molecular attributes. This suggests that mixture interactions do not dramatically reconfigure the set of activated $\mathrm{M} / \mathrm{Ts}$ in the MOB under these conditions.

Although there was strong agreement between the presence of mixture and component responses, response magnitudes were often affected. When mixture response magnitudes were plotted against those of components, data points were clustered along the diagonal, reflecting the correlation between the two (Fig. 4C). However, the majority of mixture responses were somewhat smaller than single-component responses (Fig. $4 C, D$ ), and, in a small number of cases, mixture responses were strongly suppressed relative to the active component (Fig. $4 C$, arrowheads) (mixtures were compared with the maximal component response, which in most cases was also the only effective component). Overall, the mean mixture response across the population was significantly reduced relative to single-component responses (Fig. 4E) (52.4 \pm 19.3\%, mean \pm SEM; $p<0.02$, paired $t$ test; $n=26$ ). Thus, although the set of active odorants was typically consistent between mixtures and components, mixtures produced a general suppression of evoked firing rates that was likely generated by interactions with local inhibitory circuits. Although pronounced differences in mixtures and component responses did occur, these were rare, and it is not clear whether they resulted from interactions at the level of local circuits or of upstream receptor neurons.

\section{Wide-scale M/T screening}

Mixture responses provided a basis for rapid and accurate screening by reliably indicating responses to individual odorants. This enabled testing with a much larger set of 348 compounds encompassing a large segment of olfactory space (supplemental Table 1, available at www.jneurosci.org as supplemental material), revealing a more comprehensive view of $\mathrm{M} / \mathrm{T}$ selectivity and tuning. We tested 61 additional neurons with this expanded panel (36 with mixtures and components, 6 cells with mixtures only, and 19 with single compounds alone), for a total dataset of $>12,000$ odorant$\mathrm{M} / \mathrm{T}$ combinations in 82 neurons. Typically, only a few mixtures activated a single $\mathrm{M} / \mathrm{T}$, each of which commonly contained a single active component (Fig. 5A). Multiple compounds activating the same neuron also frequently possessed common atomic connectivity (Fig. 5A). Many cells demonstrated such strong selectivity that responses would be unlikely to be revealed with a smaller panel (Fig. 5B), illustrating the importance of a large odorant set in evaluating MOB coding.

We quantified M/T selectivity across the full dataset using two different approaches. First, we again used the simple method of considering the fraction of odorants that on average activated each $\mathrm{M} / \mathrm{T}$, limiting analysis only to the set of stimuli that were explicitly tested individually. The median fraction of odorants producing $\mathrm{M} / \mathrm{T}$ activation $\geq 5 \mathrm{~Hz}$ in any time bin was $8.8 \%$ (Fig. $5 C$ ) (mean of $14.2 \% ; 3174$ odorant-M/T combinations, 66 cells in 36 animals, 20-168 odorants per cell). Similar results were obtained classifying cells using a statistical threshold of $\pm 3 \mathrm{SD}$ (Fig. 5D) (median of 12.0\%; mean of 18.9\%, 53 cells; see Materials and Methods), although this could not be applied to a substantial subset of neurons with negligible resting activity. Applying thresholds that were more stringent, but still small relative to the size of evoked responses, revealed a still smaller population of strongly responding neurons (supplemental Fig. 3, available at www.jneurosci.org as supplemental material). Therefore, using this simple and approximate measure, we found that $\mathrm{M} / \mathrm{T}$ s were responsive to only a small fraction of applied odorants.

However, classifying neuronal activity as either responsive or unresponsive only partially describes stimulus selectivity, because response strengths also varied across active odorants (Figs. 2,3 ), and arbitrary detection criteria could bias results (supplemental Fig. 3, available at www.jneurosci.org as supplemental material). We therefore also quantified selectivity using the lifetime sparseness index $S_{L}$, a measure that is independent of detection thresholds and is based on the full distribution of response strengths to all stimuli. $S_{L}$ ranges from 0 , for an entirely nonselective cell that responds equally to all stimuli, to 1 , for a neuron that responds solely to a single stimulus (Willmore and Tolhurst, 


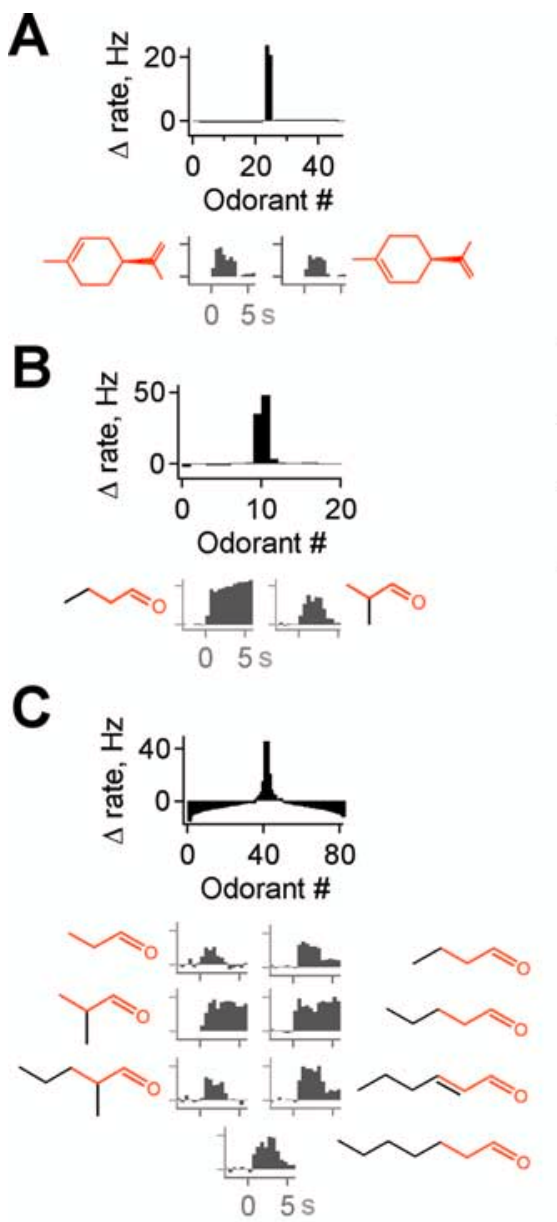

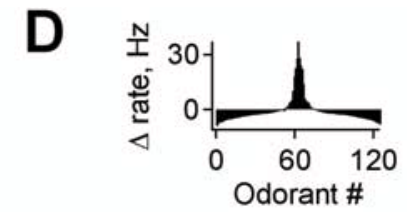
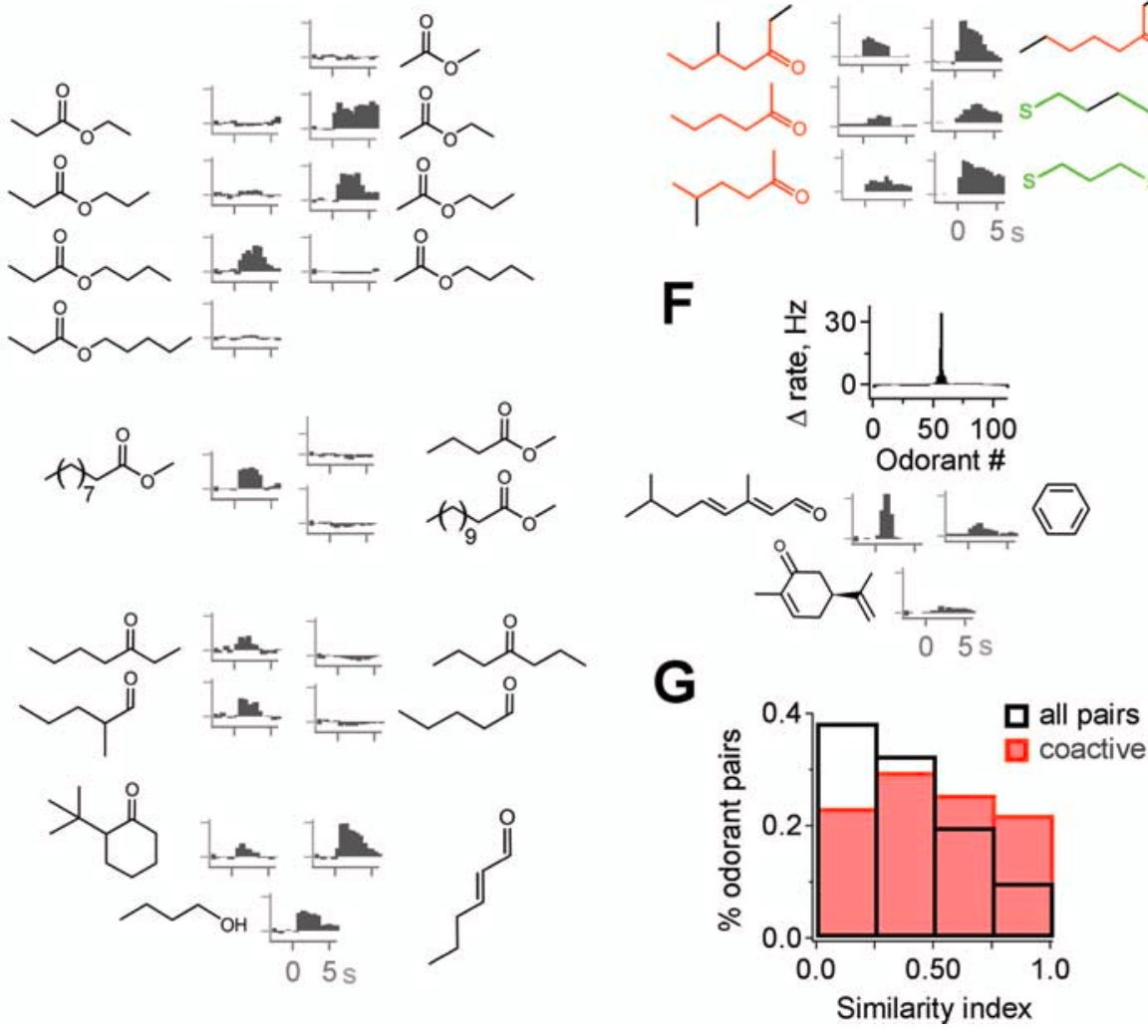

Figure 6. Molecular structures of compounds coactivating M/Ts. A-C, Multiple odorants producing activation of an individual neuron frequently share common functional groups or clear structural overlap. Top, Distribution of response strengths across odorants; compounds shown below are highlighted in red. Bottom, Structures of the most highly active odorants (left), with common features shown in color, and PSTHs showing the activity evoked by each (right). $\boldsymbol{D}, \mathrm{M} / \mathrm{Ts}$ further discriminate among highly similar odorants, suggesting that global molecular shape also influences tuning. Although receptive ranges are highly restricted, they also extend to compounds with a variety of functional groups and carbon chain structures. $E$, Example in which subsets of coactive compounds are similar to each other (red and green structures), but similarity is not consistent across the entire group, indicating that the features activating $M / T s$ are not obvious from simplified structural diagrams or limited to clear chemical categories. $F$, Occasionally, coactive odorants were not obviously similar, emphasizing the requirement for extended sampling to determine tuning. G, Distribution of molecular similarity for coactive odorants (red) compared with the distribution for all possible pairwise combinations of odorants in the screen (black). The population of coactive odorants is significantly more similar than the full panel ( $p<10^{-6}$, Kolmogorov-Smirnov test; 169 pairs of coactive odorants).

2001; Perez-Orive et al., 2002) (see Materials and Methods). Overall, lifetime sparseness for $\mathrm{M} / \mathrm{T}$ s was also high: median $\mathrm{S}_{\mathrm{L}}$ was $0.86(0.81 \pm 0.19$, mean $\pm \mathrm{SE})$, and $70 \%$ of cells had $\mathrm{S}_{\mathrm{L}} \geq$ 0.80 (Fig. $5 E$ ) ( $n=57$, calculated for cells tested with $\geq 20$ individual odorants; see Materials and Methods). For illustration, $\mathrm{S}_{\mathrm{L}}$ $=0.85$ and 0.92 for the neurons in Figures $5 A$ and $2 A$, respectively, close to the median value.

In summary, both of these measures indicated that M/Ts demonstrate strong selectivity and sparseness when tested with hundreds of odorant stimuli spanning a wide range of chemical and perceptual categories. We also note that these measures may underestimate specificity, because they were based on responses from individual compounds, and individual sampling was directed by initial mixture testing to include active stimuli.

\section{Chemical odorant structure and $\mathrm{M} / \mathrm{T}$ receptive range}

The high selectivity of $\mathrm{M} / \mathrm{T}$ responses implied that they signal the presence of specific stimulus characteristics present on only a restricted set of odorants. To evaluate the relationship between $\mathrm{M} / \mathrm{T}$ activity and odorant structure, we compared multiple odorants that produced distinct responses in a single neuron. Despite wide structural variation across the test panel, the group of coactive compounds that emerged from the screen frequently possessed clearly corresponding functional groups or chemical features (Fig. 6A-D) (see also Figs. 2D, 5A). This confirms that shared atomic connectivity is a clear determinant of M/T responses, presumably deriving from common molecular structures that interact with the specific OR subtype providing primary sensory input to the neuron. However, receptive range boundaries could also be sharply demarcated even between similar members of the same chemical class, indicating that M/Ts do not simply respond to all odorants with highly related structures. Responses often varied dramatically among compounds differing by only a single carbon atom in their structure, demonstrating selectivity even within a restricted region of chemical space (Fig. $6 D)$. This suggests that, whereas chemical features such as functional group have a clear role in determining $\mathrm{M} / \mathrm{T}$ activity, responses are not specified solely by the presence or absence of these features but also by global odorant structure, which may either alter its interaction with ORs or produce suppression through local inhibitory circuits.

Although these findings were consistent with other studies 
A

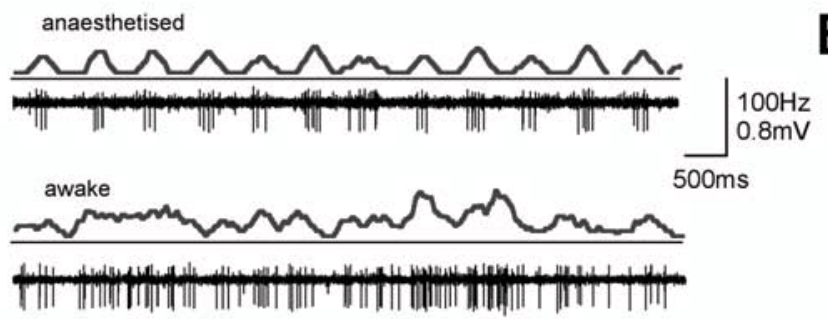

B

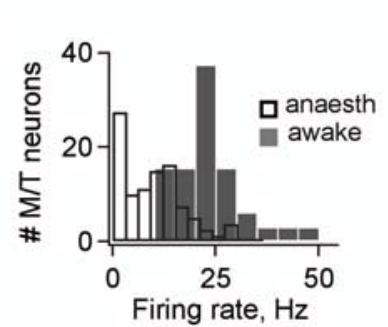

C i

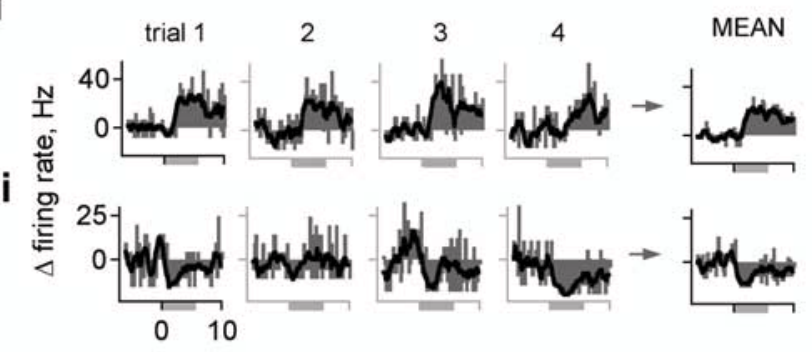

D

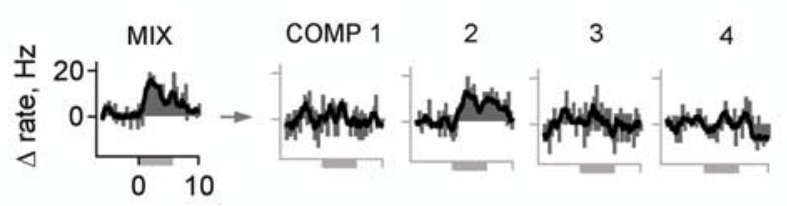

E

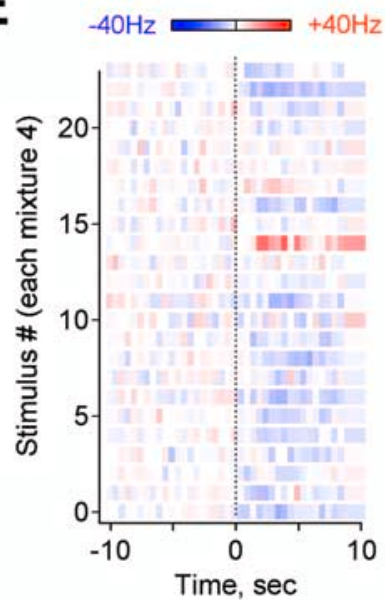

F

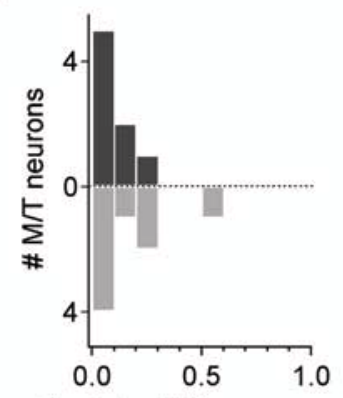

$\%$ mixts eliciting response

\section{G}

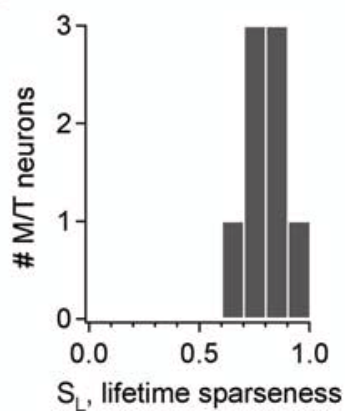

Figure 7. $M / T$ odorant responses are also selective in alert mice. $\boldsymbol{A}$, Comparison of $M / T$ activity recorded using chronically implanted microdrives under anesthesia (top) and during active investigation (bottom), showing increased activity and variability. $\boldsymbol{B}$, Distribution of unstimulated firing rates for all neurons recorded in awake animals (solid gray bars) compared with anesthesia (open black bars; mean, $23.2 \pm 8.0$ vs $9.3 \pm 7.6 \mathrm{~Hz} ; p<10^{-12}, t$ test). $C$, Odorant-evoked firing rates for an $\mathrm{M} / \mathrm{T}$ tested with repeated presentations of the same mixture (left to right), showing that responses are repeatable across multiple trials as in anesthetized animals. Two different mixtures producing activation and suppression of the same M/T are shown in $\boldsymbol{i}$ and $\boldsymbol{i}$, respectively. $\boldsymbol{D}$, Evoked $M / T$ firing rates for an effective mixture (left) and individual components (right). Neurons activated by a mixture also typically responded to single components. $E$, $M / T$ tested with 25 mixtures, averaged over four trials. This neuron was activated by a single stimulus but was also atypically inhibited by the majority of mixtures. $F, G$, Population selectivity measurements for M/Ts recorded in alert animals. Cells were excited or inhibited by $10.0 \pm 2.8$ and $16.1 \pm 6.2 \%$ of mixtures, respectively (mean change in firing rate $\geq 5 \mathrm{~Hz}$ ). Mean lifetime sparseness $S_{L}=0.79 \pm 0.04$ (mean $\pm \mathrm{SE} ; n=8$ cells in 5 animals).

showing that $\mathrm{M} / \mathrm{T}$ s respond to compounds with similar chemical connectivity, additional tuning features were revealed by testing with a broadly distributed panel independently of assumptions about response properties. Although some neurons had receptive ranges that appeared confined to a particular functional group and set of similar carbon chain lengths (Fig. $6 \mathrm{~B}, \mathrm{C}$ ), others were activated by compounds with a wider range of atomic connectivity. For example, although the M/T shown in Figure $6 D$ showed pronounced selectivity even among highly similar ester compounds (top), additional odorants activating the cell variously contained ketone, aldehyde, and alcohol groups, and included carbon chains that could be straight, branched, or cyclic, and either short or long for the same functional group (bottom). We also found $\mathrm{M} / \mathrm{Ts}$ that were activated by odorants that did not universally share any clear common feature, despite the fact that the cells retained strong stimulus specificity and there was structural overlap across some compounds (Fig. 6E). Infrequently, neurons even responded to stimuli lacking any overt correspondence with each other, although again maintaining stimulus specificity (Fig. 6F) (see also Fig. 1D). Thus, although M/T receptive ranges are highly restricted within chemical space, they are not necessarily confined to a particular chemical category or easily predicted by simplified representations of molecular structure. Rather, odorants with diverse atomic composition and connectivity may still possess common characteristics that allow them to coordinate with binding sites on the OR subtype sending inputs to the neuron.
To assess the overall similarity of coactive stimuli across the dataset, we calculated the fraction of shared molecular attributes for all pairwise combinations of the compounds that activated each individual neuron (see Materials and Methods). This population of coactive compounds was significantly more similar than predicted by the distribution of all possible pairwise odorant combinations across the full stimulus panel, providing quantitative support for a broad role of molecular features in determining M/T activity (Fig. $6 G)\left(p<10^{-6}\right.$, Kolmogorov-Smirnov test; 169 pairs of coactive stimuli). Altogether, by screening with a large and highly diverse odorant set, we found that the few compounds activating a single neuron regularly shared common atomic connectivity, indicating that their molecular structure plays a central role in shaping selective tuning of $\mathrm{M} / \mathrm{T}$ s. However, the stimuli evoking $\mathrm{M} / \mathrm{T}$ activity were not necessarily limited to an easily identifiable segment of odor space, suggesting that the chemical dimensions encoded by the MOB are not always aligned with obvious chemical categories such as functional group.

\section{$\mathrm{M} / \mathrm{T}$ selectivity in awake animals}

An important consideration is the extent to which M/T tuning properties measured under anesthesia reflect olfactory processing in awake behaving animals, in which sensory responses could be affected by behavioral state or learned associations (Kay and Laurent, 1999; Rinberg et al., 2006). To evaluate M/T coding in awake mice, we used chronically implanted microdrives that allow recording of clearly isolated $\mathrm{M} / \mathrm{T}$ units in freely behaving 
animals (Fee and Leonardo, 2001; Luo and Katz, 2003). As under anesthesia, cells were identified by background activity characteristics of different cell layers, recording depth, spike size and firing pattern, and reconstruction of a set of lesioned recording sites. Unstimulated $\mathrm{M} / \mathrm{T}$ activity in awake, behaving animals was more variable and on average higher than under anesthesia (Fig. $7 A, B$ ) (mean firing rates, $23.2 \pm 8.0$ vs $9.3 \pm 7.6 \mathrm{~Hz} ; p<10^{-13}, t$ test). To assess awake sensory responses under similar experimental conditions as with anesthesia, animals were placed in a small chamber in which air was exchanged at a high flow rate for control of stimulus presentation ( $500 \mathrm{cc}$ volume per $10 \mathrm{~L} / \mathrm{min}$ flow). Each odorant was presented for $6 \mathrm{~s}$ at a vapor phase concentration of $10 \mathrm{ppm}$, and mixtures were again used to expand the stimulus set ( 25 mixtures of 4 compounds each) (supplemental Table 1, available at www.jneurosci.org as supplemental material).

The general features of $\mathrm{M} / \mathrm{T}$ odorant responses in alert mice mirrored those seen under anesthesia. M/T responses to a mixture, although occurring infrequently, generated clear changes in firing rate that were consistent over several trials (Fig. 7C). Cells with mixture responses also responded to a single mixture component (Fig. 7D). Screening with a test panel of mixtures again produced activation to only one or a small number of stimuli (Fig. 7E) (25 mixtures of 4 compounds each; cells with changes in mean firing rate $\geq 5 \mathrm{~Hz}$ were classified as responsive; this neuron was atypically inhibited by a large proportion of compounds). A population analysis of responses in the awake state showed that typically only a small fraction of mixture stimuli produced excitation or suppression of $\mathrm{M} / \mathrm{Ts}$, similar to anesthetized animals (Fig. 7F) (cells were excited or inhibited by $10.0 \pm 2.8$ and $16.1 \pm$ $6.2 \%$ of mixtures, respectively, mean \pm SE; $n=8$ cells in 5 animals, each screened with $12-25$ mixtures $=48-100$ odorants, $\geq 3$ trials). Likewise, the classification-independent sparseness index $\mathrm{S}_{\mathrm{L}}$ was also high (Fig. 7G) (mean, $0.79 \pm 0.04$ ), indicating that neurons were activated specifically by one or a few mixtures rather than broadly and similarly by many stimuli. Qualitatively similar results were obtained for an six additional cells that were incompletely screened (data not shown). We rarely observed clear $\mathrm{M} / \mathrm{T}$ activation in animals freely investigating an arena containing various odor stimuli, further consistent with selectivity, and when responses did occur they were brief and variable (supplemental Fig. 4, movie 1, available at www.jneurosci.org as supplemental material). As a whole, $\mathrm{M} / \mathrm{T}$ selectivity was consistently present in both anesthetized and alert animals, indicating that selective $\mathrm{M} / \mathrm{T}$ activation is also a feature of olfactory processing in the awake state.

\section{Discussion}

Descriptions of the tuning of individual neurons, delineating the stimulus features that evoke neuronal activity, are a powerful tool for understanding sensory processing and information representation across neuronal populations (Pouget et al., 2000). Such descriptions of olfaction are complicated by the properties of odorant space, which is extremely large, discrete, and varies along ambiguous dimensions, making extensive stimulus sets necessary (Hallem and Carlson, 2006; Wilson and Mainen, 2006). Here, we screened mammalian M/Ts with $>300$ odorants with widely and systematically varying chemical structures, finding several prominent tuning characteristics. First, single neurons are sensitively and robustly activated by highly specific odorant subsets, suggesting that $\mathrm{M} / \mathrm{Ts}$ are selectively tuned to shared characteristics of these compounds. Second, although the restricted stimulus set activating a single M/T often shared obvious molecular similarity, coactive odorants could also be chemically diverse, indicating that the features relevant to coding are not simply confined to clear chemical categories. Third, odorants were typically effective whether presented singly or in mixtures, consistent with specific encoding of stimulus attributes, although mixtures generally produced suppression of evoked firing rates. Finally, robust, odorspecific activation was maintained by neurons in alert mice, showing that selectivity is also characteristic of responses in awake animals. We discuss the implications of these findings in more detail below.

\section{Basis for selectivity}

$\mathrm{M} / \mathrm{T}$ selectivity could derive from several sources. It may result from selective and homogeneous $\mathrm{M} / \mathrm{T}$ input imparted by receptor tuning (Araneda et al., 2004; Oka et al., 2006). Consistent with this, functional imaging shows that many odorants activate a small fraction of MOB glomeruli at lower stimulus intensities (Rubin and Katz, 1999; Meister and Bonhoeffer, 2001; Wachowiak and Cohen, 2001; Lin et al., 2006), suggesting activation of a small fraction of receptor types. In contrast, other recordings show promiscuous sensory neuron responses even at low concentrations (Duchamp-Viret et al., 1999). Selectivity was likely enhanced by feedback and/or feedforward inhibition generated by local MOB interneurons, potentially allowing strongly activated $\mathrm{M} / \mathrm{T}$ s to suppress weakly responding cells, as suggested previously (Harrison and Scott, 1986; Yokoi et al., 1995; Aungst et al., 2003; Cang and Isaacson, 2003; Cleland and Sethupathy, 2006). Several of our observations suggested that inhibition regulated M/T firing: suppressive responses occurred regularly (Figs. $1,2,7)$; both suppression after strong excitation and "rebound" firing at stimulus offset were occasionally observed (Fig. 5A); and responses to effective stimuli were commonly suppressed in mixtures, presumably via inhibition generated by additional unrecorded M/Ts. Although our data do not directly address the origins of selectivity, these may be revealed by experiments measuring the correspondence between MOB input and output or the effect of GABAergic inhibition on M/T odorant responses.

\section{Tuning and stimulus features}

Both physiological recordings and functional imaging suggest the MOB encodes structural odorant features, frequently characterized in terms of functional group (Mori et al., 1999, 2006). Although our findings generally accorded with this, by screening a large and distributed odorant panel, we also found that M/T tuning demonstrated additional complexity. First, specificity extended beyond basic chemical similarity: cells were not simply activated by all odorants with a common functional group and highly related structures but were also selective for distinct subsets whose relationship was not easily identifiable. Tuning was thus determined not only by specific chemical features in isolation but also by global molecular structure. Despite the highly restricted extent of tuning, we also found that effective compounds frequently spanned diverse chemical classes and carbon chain structures, and, in several instances, there was no obvious correspondence across structures of coactive stimuli. It therefore appears that the chemical attributes recognized by $\mathrm{M} / \mathrm{Ts}$ can also be present on compounds dissimilar in atomic connectivity, implying that the stimulus dimensions encoded by the MOB may consist of molecular shapes and charge distributions that can be shared by odorants with varying molecular composition.

\section{Mixture responses}

Typically, odorants were effective whether presented individually or in mixtures, consistent with a role in detecting specific molec- 
ular characteristics. However, mixture responses were commonly reduced relative to individual compounds, likely because of inhibition generated by numerous local interneurons such as granule and periglomerular cells. In most cases, presenting effective compounds in mixtures partially reduced evoked firing rates rather than dramatically changing responsiveness, so that lateral interactions appeared to broadly suppress rather than markedly reconfigure the set of activated M/Ts. Strong mixture interactions did occur rarely and may result from increased lateral inhibition with activation of related glomeruli or from antagonism at the receptor level (Yokoi et al., 1995; Araneda et al., 2004; Oka et al., 2004). Our mixtures contained small numbers of dissimilar compounds, and stronger interactions may emerge with larger mixtures or more highly related components. Nonetheless, we found a strong correspondence between odorants activating M/Ts individually and in mixtures, indicating that $\mathrm{M} / \mathrm{T}$ s encode stimulus attributes similarly under these conditions.

\section{Odorant responses in awake animals}

Factors such as arousal, attention, or associational context may modulate neuronal activity in behaving animals (Bhalla and Bower, 1997; Dave et al., 1998; Kay and Laurent, 1999; Fritz et al., 2003), making it important to assess sensory responses in the awake state. In the olfactory system, extensive descending noradrenergic, cholinergic, and serotonergic feedback pathways target the $\mathrm{MOB}$ and are known to modulate M/T activity (Shepherd and Greer, 1990; Jiang et al., 1996; Castillo et al., 1999). Mice and other animals also regulate sampling spatially and temporally by exploration and sniffing (Kepecs et al., 2006). Furthermore, anesthetic effects on complex circuit activity are poorly understood. However, we found consistently selective M/T activation in both anesthetized and alert animals, indicating that sparse responses are relevant to natural MOB function. Recent findings described increased $\mathrm{M} / \mathrm{T}$ selectivity in awake behaving mice relative to anesthesia (Rinberg et al., 2006). Our selectivity measures were approximately equal for both anesthetized and alert animals, although stimuli for alert mice consisted of mixtures of four compounds. Therefore, although differences in anesthetic and behavioral task complicate comparison, our findings may also suggest augmented selectivity in the awake state (Rinberg et al., 2006).

\section{Selectivity in other studies and systems}

Feature-selective responses agree with previous findings that $\mathrm{M} / \mathrm{Ts}$, when tested with structurally related compounds, both respond to and discriminate among multiple odorants (Imamura et al., 1992; Mori et al., 1992; Katoh et al., 1993). However, our findings contrast with others describing broad M/T activation by diverse odorants (Motokizawa, 1996) and characterizing odor information as widely distributed across a large, nonselective neuronal population (Lehmkuhle et al., 2006). Although reasons for this are unclear, considerations may include incomplete estimation of receptive ranges using small odorant sets (sampling only suboptimal stimuli), possible sampling bias (preferentially characterizing cells responsive to a limited test panel will emphasize broad tuning), or from presenting stimuli at unphysiologically high odorant concentrations.

Notably, however, in insect systems the tuning of secondorder projection neurons is consistently described as broad and nonselective, with cells frequently responding to $\geq 50 \%$ of compounds (Perez-Orive et al., 2002; Wilson et al., 2004; Mazor and Laurent, 2005) (but see Wang et al., 2003). Although again the cause of discrepancy is unclear, differences in circuit organization may favor different coding strategies. The OR repertoire is much smaller in insects than in mammals $(\sim 60-80$ vs $\sim 1000$ in the rodent) (Bargmann, 2006) and may correspondingly divide olfactory space into broader or more highly overlapping segments, possibly contributing to reliance on additional, temporal response features for encoding. The firing rate measure used in our analysis does not address or exclude a role for temporal response characteristics, such as change in respiratory phase or synchronization at various frequencies, shown to contribute to olfactory processing (Kashiwadani et al., 1999; Buonviso et al., 2006). Nonetheless, our data clearly support an identity-based coding scheme in which specific M/Ts signal specific molecular odorant characteristics by increasing their firing rate and are inconsistent with broadly distributed activity widely dispersed across the M/T population.

\section{Implications for olfactory coding}

The computations performed across successive stages of sensory processing, and the corresponding emergence of complex feature recognition are commonly thought to arise through integration or comparison of lower-level responses with simpler or broader response properties (Hubel and Wiesel, 1962; Zhang et al., 2003). Thus, knowledge of how early processing stages encode stimulus features provides a foundation for understanding these computations (Hallem and Carlson, 2006). We find that M/Ts establish pronounced feature selectivity immediately downstream of primary sensory inputs, which appears to match or exceed that emerging only at higher levels in other sensory systems (Maldonado et al., 1997; Zhang et al., 2003). This may reflect a strategy adapted to the challenges posed by chemical recognition. M/T axons project in diffuse, overlapping patterns to olfactory cortex (Zou et al., 2001), in which neurons appear to combine inputs from multiple M/Ts (Wilson, 2000; Zou et al., 2005; Lei et al., 2006; Zou and Buck, 2006) and may detect the coincidence of these inputs (Zou and Buck, 2006). Our findings suggest that these cortical circuits, which contribute to odor recognition and generation of appropriate behavior, receive information consisting of a set of selectively activated $\mathrm{M} / \mathrm{T}$ inputs, each signifying highly specific chemical characteristics of the stimulus.

\section{References}

Araneda RC, Peterlin Z, Zhang X, Chesler A, Firestein S (2004) A pharmacological profile of the aldehyde receptor repertoire in rat olfactory epithelium. J Physiol (Lond) 555:743-756.

Aungst JL, Heyward PM, Puche AC, Karnup SV, Hayar A, Szabo G, Shipley MT (2003) Centre-surround inhibition among olfactory bulb glomeruli. Nature 426:623-629.

Bargmann C (2006) Comparative chemosensation from receptors to ecology. Nature 444:295-301.

Bhalla US, Bower JM (1997) Multiday recordings from olfactory bulb neurons in awake freely moving rats: spatially and temporally organized variability in odorant response properties. J Comput Neurosci 4:221-256.

Bozza T, Feinstein P, Zheng C, Mombaerts P (2002) Odorant receptor expression defines functional units in the mouse olfactory system. J Neurosci 22:3033-3043

Buck L, Axel R (1991) A novel multigene family may encode odorant receptors: a molecular basis for odor recognition. Cell 65:175-187.

Buonviso N, Amat C, Litaudon P (2006) Respiratory modulation of olfactory neurons in the rodent brain. Chem Senses 31:145-154.

Cang J, Isaacson JS (2003) In vivo whole-cell recording of odor-evoked synaptic transmission in the rat olfactory bulb. J Neurosci 23:4108-4116.

Castillo PE, Carleton A, Vincent JD, Lledo PM (1999) Multiple and opposing roles of cholinergic transmission in the main olfactory bulb. J Neurosci 19:9180-9191.

Cleland TA, Sethupathy P (2006) Non-topographical contrast enhancement in the olfactory bulb. BMC Neurosci 7:7. 
Dave AS, Yu AC, Margoliash D (1998) Behavioral state modulation of auditory activity in a vocal motor system. Science 282:2250-2254.

Duchamp-Viret P, Chaput MA, Duchamp A (1999) Odor response properties of rat olfactory receptor neurons. Science 284:2171-2174.

Fee MS, Leonardo A (2001) Miniature motorized microdrive and commutator system for chronic neural recording in small animals. J Neurosci Methods 112:83-94.

Fritz J, Shamma S, Elhilali M, Klein D (2003) Rapid task-related plasticity of spectrotemporal receptive fields in primary auditory cortex. Nat Neurosci $6: 1216-1223$

Gurden H, Uchida N, Mainen ZF (2006) Sensory-evoked intrinsic optical signals in the olfactory bulb are coupled to glutamate release and uptake. Neuron 52:335-345.

Hallem EA, Carlson JR (2006) Coding of odors by a receptor repertoire. Cell 125:143-160.

Harrison TA, Scott JW (1986) Olfactory bulb responses to odor stimulation: analysis of response pattern and intensity relationships. J Neurophysiol 56:1571-1589.

Hubel DH, Wiesel TN (1962) Receptive fields, binocular interaction, and functional architecture in the cat's visual cortex. J Physiol (Lond) 160:106-154.

Imamura K, Mataga N, Mori K (1992) Coding of odor molecules by mitral/ tufted cells in rabbit olfactory bulb. I. Aliphatic compounds. J Neurophysiol 68:1986-2002.

Jiang M, Griff ER, Ennis M, Zimmer LA, Shipley MT (1996) Activation of locus coeruleus enhances the responses of olfactory bulb mitral cells to weak olfactory nerve input. J Neurosci 16:6319-6329.

Kashiwadani H, Sasaki YF, Uchida N, Mori K (1999) Synchronized oscillatory discharges of mitral/tufted cells with different molecular receptive ranges in the rabbit olfactory bulb. J Neurophysiol 82:1786-1792.

Katoh K, Koshimoto H, Tani A, Mori K (1993) Coding of odor molecules by mitral/tufted cells in rabbit olfactory bulb. II. Aromatic compounds. J Neurophysiol 70:2161-2175.

Kay LM, Laurent G (1999) Odor- and context-dependent modulation of mitral cell activity in behaving rats. Nat Neurosci 2:1003-1009.

Kelliher ZR, Ziesmann J, Munger SD, Reed RR, Zufall F (2003) Importance of the CNGA4 channel gene for odor discrimination and adaptation in behaving mice. Proc Natl Acad Sci USA USA 100:4299-4304.

Kepecs A, Uchida N, Mainen ZF (2006) The sniff as a unit of olfactory processing. Chem Senses 31:167-179.

Laska M, Joshi D, Shepherd GM (2006) Olfactory sensitivity for aliphatic aldehydes in CD-1 mice. Behav Brain Res 167:349-354.

Lehmkuhle MJ, Normann RA, Maynard EM (2003) High-resolution analysis of the spatio-temporal activity patterns in rat olfactory bulb evoked by enantiomer odors. Chem Senses 28:499-508.

Lehmkuhle MJ, Normann RA, Maynard EM (2006) Trial-by-trial discrimination of three enantiomer pairs by neural ensembles in mammalian olfactory bulb. J Neurophysiol 95:1369-1379.

Lei H, Mooney R, Katz LC (2006) Synaptic integration of olfactory information in mouse anterior olfactory nucleus. J Neurosci 26:12023-12032.

Lin DY, Zhang SZ, Block E, Katz LC (2005) Encoding social signals in the mouse main olfactory bulb. Nature 434:470-477.

Lin DY, Shea SD, Katz LC (2006) Representation of natural stimuli in the rodent main olfactory bulb. Neuron 50:937-949.

Luo M, Fee MS, Katz LC (2003) Encoding pheromonal signals in the accessory olfactory bulb of behaving mice. Science 299:1196-1201.

Maldonado PE, Godecke I, Gray CM, Bonhoeffer T (1997) Orientation selectivity in pinwheel centers in cat striate cortex. Science 276:1551-1555.

Mazor O, Laurent G (2005) Transient dynamics versus fixed points in odor representations by locust antennal lobe projection neurons. Neuron 48:661-673.

Meister M, Bonhoeffer T (2001) Tuning and topography in an odor map on the rat olfactory bulb. J Neurosci 21:1351-1360.
Meredith M (1986) Patterned response to odor in mammalian olfactory bulb: the influence of intensity. J Neurophysiol 56:572-597.

Mori K, Mataga N, Imamura K (1992) Differential specificities of single mitral cells in rabbit olfactory bulb for a homologous series of fatty acid odor molecules. J Neurophysiol 67:786-789.

Mori K, Nagao H, Yoshihara Y (1999) The olfactory bulb: coding and processing of odor molecule information. Science 286:711-715.

Mori K, Takahashi YK, Igarashi KM, Yamaguchi M (2006) Maps of odorant molecular features in the mammalian olfactory bulb. Physiol Rev 86:409-433.

Motokizawa F (1996) Odor representation and discrimination in mitral/ tufted cells of the rat olfactory bulb. Exp Brain Res 112:24-34.

Oka Y, Omura M, Kataoka H, Touhara K (2004) Olfactory receptor antagonism between odorants. EMBO J 23:120-126.

Oka Y, Katada S, Omura M, Suwa M, Yushihara Y, Touhara K (2006) Odorant receptor map in the mouse olfactory bulb: in vivo sensitivity and specificity of receptor-defined glomeruli. Neuron 52:857-869.

Passe DH, Walker JC (1985) Odor psychophysics in vertebrates. Neurosci Biobehav Rev 9:431-467.

Perez-Orive J, Mazor O, Turner GC, Cassenaer S, Wilson RI, Laurent G (2002) Oscillations and sparsening of odor representations in the mushroom body. Science 297:359-365.

Pouget A, Dayan P, Zemel R (2000) Information processing with population codes. Nat Rev Neurosci 4:826-831.

Ressler KJ, Sullivan SL, Buck LB (1994) Information coding in the olfactory system: evidence for a stereotyped and highly organized epitope map in the olfactory bulb. Cell 79:1245-1255.

Rinberg D, Koulakov A, Gelperin A (2006) Sparse odor coding in awake behaving mice. J Neurosci 26:8857-8865.

Rubin BD, Katz LC (1999) Optical imaging of odorant representations in the mammalian olfactory bulb. Neuron 23:499-511.

Shepherd GM, Greer CA (1990) Olfactory bulb. In: The synaptic organization of the brain (Shepherd GM, ed), pp 133-169: New York: Oxford UP.

Wachowiak M, Cohen LB (2001) Representation of odorants by receptor neuron input to the mouse olfactory bulb. Neuron 32:723-735.

Wang JW, Wong AM, Flores J, Vosshall LB, Axel R (2003) Two-photon calcium imaging reveals an odor-evoked map of activity in the fly brain. Cell 112:271-282.

Wellis DP, Scott JW, Harrison TA (1989) Discrimination among odorants by single neurons of the rat olfactory bulb. J Neurophysiol 61:1161-1177.

Willmore B, Tolhurst DJ (2001) Characterizing the sparseness of neural codes. Network 12:255-270.

Wilson DA (2000) Comparison of odor receptive field plasticity in the rat olfactory bulb and anterior piriform cortex. J Neurophysiol 84:3036-3042.

Wilson RI, Mainen ZF (2006) Early events in olfactory processing. Annu Rev Neurosci 29:163-171.

Wilson RI, Turner GC, Laurent G (2004) Transformation of olfactory representations in the Drosophila antennal lobe. Science 303:366-370.

Yokoi M, Mori K, Nakanishi S (1995) Refinement of odor molecule tuning by dendrodendritic synaptic inhibition in the olfactory bulb. Proc Natl Acad Sci USA 92:3371-3375.

Zhang LI, Tan AY, Schreiner CE, Merzenich MM (2003) Topography and synaptic shaping of direction selectivity in primary auditory cortex. Nature 424:201-205.

Zou Z, Buck LB (2006) Combinatorial effects of odorant mixes in olfactory cortex. Science 311:1477-1481.

Zou Z, Horowitz LF, Montmayeur JP, Snapper S, Buck LB (2001) Genetic tracing reveals a stereotyped sensory map in the olfactory cortex. Nature 414:173-179.

Zou Z, Li F, Buck LB (2005) Odor maps in the olfactory cortex. Proc Natl Acad Sci USA 102:7724-7729. 